\title{
The Content and Treatment of Prisoners \\ of war During the First World War \\ (on the example of the Kostroma and Yaroslavl provinces)
}

\section{A. M. Chapaeva ${ }^{1}$}

${ }^{1}$ P. G. Demidov Yaroslavl State University, 14 Sovetskaya str., Yaroslavl 150003, Russian Federation

DOI: $10.18255 / 1996-5648-2021-2-184-193$

Research article Full text in Russian

This article is devoted to the content of prisoners of war in the Kostroma and Yaroslavl provinces during the First World War. The international and Russian legal framework for the detention of prisoners of war is indicated, which prescribes the conditions for providing medical care, the use of labor and the treatment of officers and lower ranks. Examples of the content of prisoners of war and the attitude of the local population to military prisoners are given. The approximate expenses for the maintenance of prisoners of war in the specified provinces are shown. The generaliter information concerning equipment with medical and disinfection equipment is given. The analysis of archival documents and publications concerning the maintenance of prisoners of war is carried out.

Keywords: World War I; prisoners of war; Kostroma province; Yaroslavl province; medical care; The Hague Convention

INFORMATION ABOUT AUTHORS

Chapaeva, Anna M. | E-mail: anna.chapaeva.80@mail.ru

Postgraduate 


\section{Содержание и лечение военнопленных в период Первой мировой войны (на примере Костромской и Ярославской губерний)}

\section{А. М. Чапаева ${ }^{1}$}

${ }^{1}$ Ярославский государственный университет им. П. Г. Демидова, ул. Советская, 14 , Ярославль, 150003, Российская Федерация

DOI: 10.18255/1996-5648-2021-2-184-193

УДК $930+94(47)$

Научная статья

Полный текст на русском языке

Данная статья посвящена содержанию военнопленных в Костромской и Ярославской губерниях в период Первой мировой войны. Главный акцент сделан на оценку международной и российской законодательной базы по содержанию военнопленных, где прописаны условия оказания медицинской помощи, использование труда и обращение с офицерами и нижними чинами. Приведены примеры содержания военнопленных и примерные расходы на них. В статье рассматриваются сюжеты, связанные с оказанием медицинской помощи пленным (на примере Костромской и Ярославской губерний), и отношение к ним со стороны местного населения. Приведены обобщённые сведения, касающиеся оснащения медицинским и дезинфекционным оборудованием, и анализ архивных документов и публикаций в отношении содержания военнопленных.

Ключевые слова: Первая мировая война; военнопленные; Костромская губерния; Ярославская губерния; медицинская помощь; Гаагская конвенция

\section{ИНФОРМАЦИЯ ОБ АВТОРАХ}

\begin{tabular}{l|l} 
Чапаева, Анна Михайловна & $\begin{array}{l}\text { E-mail: anna.chapaeva.80@mail.ru } \\
\text { Аспирант }\end{array}$
\end{tabular}

Начало XX века ознаменовалось одним из крупнейших мировых конфликтов в истории человечества. Войну 1914-1918 гг. некоторое время называли Второй отечественной, а после войны 1939-1945 гг. - Первой мировой. Она привела к международному экономическому кризису, унесла много жизней. Миллионы людей стали военнопленными; их судь- 
Чапаева А. М.

бы были сломаны унижениями, через которые им пришлось пройти. Военные действия характеризовались игнорированием установленных международных норм ведения войны и постоянными нарушениями всех ранее заключённых международных договоров воевавшими государствами. Н. М. Жданов в работе «Русские военнопленные в мировой войне» отмечал, что военный конфликт начался с нарушения гарантированного нейтралитета Бельгии и Люксембурга со стороны Германии. Он подробно разобрал положение русских военнопленных в годы Первой мировой войны [1]. К сожалению, подобный анализ отсутствует по отношению к немецким военнопленным на территории России.

Постановления Брюссельской и Петербургской деклараций и Гаагских конференций по поводу военнопленных постоянно нарушались воюющими сторонами. Положения Женевской конференции не соблюдались, хотя именно они гарантировали права и прерогативы Красного Креста и военно-санитарных учреждений во время оказания помощи пленным. По итогам второй Гаагской конвенции в 1907 г. было принято Постановление о правовом и материальном положении военнопленных (статьи I - XX отдела I Положения о законах и обычаях сухопутной войны). Согласно статье 1 положения военные законы, права и обязанности применялись не только к армии, но и к ополчению и добровольческим отрядам, если они открыто носили оружие и соблюдали в своих действиях законы и обычаи войны. В соответствии со статьей 3 вооружённые силы воюющих сторон могли состоять из сражающихся и несражающихся. Те и другие в случае захвата неприятелем пользовались правами военнопленных.

Права военнопленных заключались в следующем: они находились во власти неприятельского правительства, а не отдельных лиц или отрядов, взявших их в плен. С военнопленными надлежало обращаться более или менее гуманно. Всё, что принадлежало им лично, кроме оружия, лошадей и военных бумаг, оставалось их собственностью и не подлежало изъятию. Государство могло привлекать их к работам, которые не должны были быть слишком обременительны и не могли иметь никакого отношения к военным действиям. Военнопленным было разрешено работать по своей специальности на государство или на частных лиц. Заработок пленных предназначался для улучшения их положения, а остаток должен был им выдаваться при освобождении за вычетом расходов на содержание [1, с. 21].

Содержание в Российской империи пленных, взятых в период Первой мировой войны, являлось достаточно дорогостоящим делом для государства, что усугубило и без того тяжелое экономическое положение в стране. Кроме того, достаточно часто пленные являлись переносчиками различных эпидемических заболеваний в регионы России. 
Содержание и лечение военнопленных в период Первой мировой войны...

Исследователи, изучающие положение военнопленных в годы Первой мировой войны, отзываются о соблюдении Гаагской конвенции неоднозначно. В. В. Корнеев в своём труде «Концентрационные лагеря в России в годы Первой мировой войны» [2] говорит о любой посильной помощи военнопленным, в том числе и медицинской не только со стороны государства, но и от населения. Б. И. Ниманов в работе «Содержание иностранных военнопленных на территории России в годы Первой мировой войны» обращает внимание на то, что конвенция не соблюдалась многими государствами, в том числе Россией [3].

Возможно, на территории Сибири, где находилось значительное количество лагерей для военнопленных, нарушения имелись, но в Костромской и Ярославской губерниях решения, принятые на 1-й и 2-й мирной конференции в Гааге, старались соблюдать, о чем свидетельствуют изученные нами документы Государственного архива Костромской области (ГАКО) и Государственного архива Ярославской области (ГАЯО).

Первые военнопленные поступили в Ярославскую губернию в сентябре - октябре 1914 г. 786 раненых немцев и австрийцев прибыли на железнодорожный вокзал г. Рыбинска. Оттуда на конных экипажах и на руках конвоиров (ввиду тяжелого фризического состояния) они были направлены в госпиталь при Карякинском училище и во второе здание биржи, где и были размещены. Примерно в то же время первые военнопленные поступили на лечение в Чухломской уезд Костромской губернии.

16 сентября 1914 г. вводились в действие «Правила о порядке предоставления военнопленных для исполнения казённых и общественных работ в распоряжение заинтересованных в том ведомств» [4, л. 7]. Большинство военнопленных, которые направлялись в Костромскую и Ярославскую губернии для работы на предприятиях, имели различные заболевания. Остро стоял вопрос об их содержании и способах лечения. Среди прочего в п. 13 Правил было прописано, что в обязанности начальника работ входила организация надлежащей медицинской помощи заболевшим военнопленным; а п. 14 гласил, что обо всех переменах в составе военнопленных: смерти, побеге, заболевании, а также наиболее важных происшествиях - начальник работ немедленно должен был информировать надлежащего воинского начальника, который безотлагательно должен был сообщать это военному министру [4, л. 7 об.]. Согласно правилам, заболевшие военнопленные, офицеры и нижние чины получали врачебную помощь на общих основаниях и принимались на излечение в ближайшие военные и гражданские заведения наравне с теми же чинами русских войск [4, л. 37].

Пленные содержались в условиях, не унижающих их человеческое достоинство. Газета «Рыбинские известия» сообщала о том, что в дни 
Чапаева А. М.

празднования Рождества 1914 г. главный врач сводного 21-го госпиталя Шенгеладзе устроил для раненых немцев праздничные елки и передал подарки, принесенные местными купчихами [5].

Захваченный в плен медицинский персонал германской, австрийской и турецкой армий работал по своей специальности и получал за работу жалование, включающее в себя основной оклад и "добавочные деньги» (столовые, квартирные, деньги на найм прислуги). В госпиталях оплата для военнопленного персонала производилась по соответствующим ставкам:

1) студента с «зауряд-врачами» (категория военнослужащих Российской императорской армии, которая была задействована при недостатке медицинского персонала, для замещения соответствующих должностей в мобилизуемых частях войск и военно-врачебных заведениях военного времени) 11 разряда;

2) младшего врача в обер-офицерском чине с младшими врачами, состоящими на службе менее 4 лет;

3) служащих в офицерских чинах с состоящими на службе свыше 8 лет;

4) старшего врача и занимающих высшие должности в соответствии с медицинскими чинами русской армии.

Для определения служебного положения упомянутых выше военнопленных брали собственноручные расписки с точным указанием звания и должностей [6, л. 4]. Указанные сведения подтверждают гуманное обращение российских властей с военнопленными в Костромской и Ярославской губерниях и выплаты им достойного жалования.

2 июня 1916 г. начальником штаба Петроградского округа подписан циркуляр № 44221, который обязывал извещать штаб округа о каждой поступающей партии военнопленных в губернию [7, л. 1]. Текст доклада составлял полицмейстер того или иного города или уездный исправник, которые затем передавали информацию губернаторам, а те, в свою очередь, в штаб округа. Туда же необходимо было сообщать об обеспечении военнопленных санитарной помощью, охраной, довольствием и надзором. После оглашения требования губернаторам начали поступать сообщения о количестве военнопленных и о состоянии их здоровья. Так, например, 24 июля 1916 г. в Ярославское губернское правление поступила телеграмма от Любимского уездного исправника о том, что прибыло 146 подданных Турции, 388 пленных австрийцев и 814 пленных германцев. Все военнопленные, осмотренные железнодорожным врачом, по его мнению, оказались здоровы [7, л. 7]. Однако в ряде случаев железнодорожные врачи ставили неправильные диагнозы или не замечали имеющихся у военнопленных заболеваний. Так, например, в Романово-Борисоглебске же- 
Содержание и лечение военнопленных в период Первой мировой войны...

лезнодорожный врач не выявил у 220 военнопленных австрийцев цингу [7, л. 15].

Из-за тяжелой обстановки военного времени наблюдались случаи, когда военнопленные умирали во время транспортировки к месту заключения или прибывали больными и обмороженными. Так, 22 марта 1916 г. ярославскому губернатору поступило письмо из Костромско-Ярославского управления земледелия и государственных имуществ о том, что в январе Гостовскому и Шортюжинскому отделению Костромских лесотехнических заводов для работ по возведению заводов прислали партию военнопленных из Поволжья. Многие из них получили обморожения по дороге. Свыше 50 человек, непригодных для работы, было отправлено на лечение в крупный железнодорожный узел Котельнич (ныне город в Кировской области). Остальных приняли на строительные работы в указанные лесотехнические заводы в надежде на то, что они со временем поправятся и смогут принять участие в так называемом «нулевом цикле» и возведении необходимых промышленных сооружений. В итоге из большой партии пленных еще 90 человек обмороженных и больных военнопленных не смогли участвовать в строительстве заводов, так как им требовалась госпитализация.

В сложившейся ситуации сначала заводоуправление обратилось сначала за помощью к костромскому губернатору с просьбой о содействии в устройстве больных военнопленных. В ответ губернатор написал, что ситуация ему неясна, соответственно, и помочь он ничем не может. Вследствие вышеизложенного заводоуправление попросило устроить больных военнопленных в одном из госпиталей Ярославской губернии, куда людей можно было бы доставить по железной дороге [8, л. 11].

В отношении того, что военнопленные поступали больными на назначенные работы, костромской губернатор отвечал, что военным министром установлен специальный порядок приёма поступивших на работы и обратной сдачи их военному начальнику. В соответствии с ним ведомство, получавшее для работы военнопленных, должно было во время сдачи ему последних производить их осмотр. На тех, кто оказывался больными, следовало немедленно составлять акты. В них необходимо было указывать причины отказа для принятия пленных на работу, а именно их болезненное состояние. Тот же порядок соблюдался и при возврате военнопленных с работ. Нездоровые пленные должны были оставаться на излечении у того ведомства, у которого, находясь на работе, они заболели. Лишь в исключительных случаях, например при скоплении большого числа больных заразной болезнью и при угрозе эпидемии, могла появиться необходимость в сосредоточении пленных в особо изолированных пунктах [9, л. 120]. 
Питание военнопленных в губерниях рассчитывалось, исходя из экономического положения региона. Так, в Костромской и Ярославской губерниях нормы питания пленных были примерно одинаковы. Приведём пример, согласно средней норме питания военнопленных на человека в эвакуационном госпитале № 23 по Ярославской губернии. Мясо свежее 1/2 фунта (226 гр.); солонина $3 / 4$ фунта (340 гр.) с расчётом варки 2-3 раза в неделю свежее и 4 раза солонина; для каши пшённой крупы 36 золотников (153 гр.); хлеба чёрного 2,5-3,0 фунта (1132-1359 гр.) или 1 фунт (453 гр.) белого; макарон, рису, перловки манки для засыпки супа 8 золотников (34 гр.); соли 2 золотника (8,5 гр.); зелени сушёной 1 золотник (4 гр.), если суп картофельный, то 1/2 фунта (226 гр.) картофеля на человека. Для ужина, как правило, варили снетки (небольшая рыбка длиной до 18 см (обычно не более 10 см), типичной массой 6-8 г.) [10] с картофелем, из расчёта снетков по 18 золотников (77 гр.) на человека. Плиточный чай $1 / 2$ золотника (2 гр.) на человека, сахар 6,5 золотников (28 гр.) на человека. Стоимость питания одного военнопленного по настоящей норме довольствия выражалась в следующих цифрах: мясо - 11 руб. 25 коп., картофель - 0,75 коп., зелень - 0,30 коп., соль - 0,05 коп., пшено - 2 руб., хлеб 10 руб. 5 коп., чай - 1 руб. 5 коп., сахар - 1 коп. Итого: 29 руб. 35 коп. [9, л. 2]. Аналогичная ситуация была в Костромской губернии [10, л. 19].

Вышеприведенные сведения свидетельствуют о достаточно сбалансированном питании пленных, вполне достаточном для поддержания их физического состояния на удовлетворительном уровне, которое соответствовало международным признанным медицинским нормам питания в изучаемый период времени.

В Ярославской губернии большое количество военнопленных было размещено недалеко от железнодорожной станции Семибратово, в селе Исады (ныне Ярославская область, Ростовский район). Именно там располагалась усадьба и пятиэтажная мельница одного из богатейших предпринимателей губернии, почётного потомственного купца первой гильдии Александра Ивановича Вахрамеева. Всего под опекой представителя известного ярославского купеческого рода находилось более 2000 раненых военнопленных. Для проведения санитарной обработки пленных А. И. Вахрамеев закупил на свои собственные средства значительное количество дезинфекционных камер «Гелиос» [8, л. 28]. Масштабы его закупок явились рекордными для Костромской и Ярославской губерний, что позволило обеспечить удовлетворительное соблюдение необходимых санитарных норм.

Лечебной частью на Исадской мельнице заведовал Д. В. Штерн. На заседании губернской земской управы 22 июля 1916 г. он сообщал, что в летний период времени в Исадах находились 2182 человека, кото- 
Содержание и лечение военнопленных в период Первой мировой войны...

рые прибыли четырымя эшелонами в течение нескольких дней. Больные военнопленные были без промедления приняты и размещены на мельнице в пятиэтажном здании. Всех прибывших решено было помыть в бане, постричь и переодеть. Водными процедурами были обеспечены 500 человек в сутки. Указанных показателей удалось достичь за счет невероятного напряжения и круглосуточной работы вспомогательного персонала, т. к., согласно санитарным правилам, единовременно в бане могли находиться не более 12 человек. Прибывали военнопленные в ужасном состоянии; многие из них не посещали баню в течение 8 месяцев, одежда на них превратилась в лохмотья. Люди были чрезвычайно истощены.

Из общего числа военнопленных только 600 больных могли передвигаться самостоятельно. У 50 \% военнопленных наблюдались цинга в запущенной форме, нефрит, тяжёлые желудочные заболевания. Среди военнопленных был один человек с подозрением на брюшной тифр и пять с подозрением на возвратный тифр.

Bcex заразных пациентов во избежание эпидемии поместили отдельно, однако уже через 9 дней появились случаи новых заражений. Все военнопленные, находящиеся в Исадах, проживали в бараках близко друг к другу на общих нарах с соломенными матрацами, что способствовало распространению инфекционных заболеваний. Бельё больных дезинфицировалось путём вываривания в котлах, одежда окуривалась серой в земляных камерах. Медперсонал, обслуживающий военнопленных, состоял из двух врачей и трёх фельдшеров, которые работали «не за страх, а за советь», без всякого ассигнования со стороны властей. Из медицинского инвентаря имелись только два градусника и небольшие запасы медикаментов.

На содержание военнопленных выделялось 15 копеек в день на человека Этой суммы в 1914-1916 гг. было достаточно для удовлетворительного питания. Для сравнения: средняя заработная плата костромских и ярославских рабочих составляла 15-20 руб. в месяц. В конце войны изза инфляции она уже не обеспечивала необходимые нормы потребления, но пленные могли подрабатывать. Тяжелобольным даже выдавалось молоко [8, л. 33].

Содержание военнопленных в Исадах было признано чрезвычайно опасным из-за возможности распространения различных эпидемиологических заболеваний среди местного населения. Тем не менее бараки не закрывались, а пленных было невозможно перемесить в другое место без риска серьезного ухудшения их физического состояния.

Анализируя состояние медицинской помощи военнопленным в Костромской и Ярославской губерниях за весь период Первой мировой войны, стоит отметить, что, несмотря на имеющиеся серьезные проблемы, 
большинство пленных содержались в соответствии с Гаагской конвенцией и «Положением о военнопленных», которое Николай II утвердил в октябре 1914 г. На помощь врачам приходили сёстры милосердия по окончании специальных курсов.

Выздоровевших военнопленных содержать было весьма обременительно для бюджета страны. Как правило, среди излечившихся преобладали фризически крепкие молодые люди. Согласно Гаагской конвенции, разрешалось принудительное использование их труда. Из Ярославской городской думы поступило предложение использовать труд военнопленных по благоустройству города на зимнее и осеннее время - от 200 до 300 человек по земляным работам и расчистке снега; в весеннее время их число могло быть увеличено. Руководителями работ и надсмотрщиками за работой военнопленных выступали городские десятники $[11$, л. 4].

В качестве профилактики различных заболеваний военнопленных в тёплое время года выводили купаться на пляж [12, с. 118]. Всем военнопленным в Ярославской и Костромской губерний разрешалось вести переписку с родственниками. Приказом начальника Костромского окружного эвакуационного пункта 4 августа 1916 г. был разработан текст для открытых писем военнопленных венгров: «Сообщаю, что я попал в русский плен. Я здоров. Жћивётся хорошо. Мой адрес...». Данный текст проверял дежурный врач отдела эвакуации лекарь Масский [13, л. 29 об.]. Аналогичные письма писались в Ярославской губернии [6, л. 7].

Первая мировая война изменила статус военнопленных. Международные соглашения начала $\mathrm{XX}$ в. определили их права и обязанности. В Костромской и Ярославской губерниях международные нормативные акты в целом выполнялись. В изучаемом регионе военнопленные часто использовались в качестве рабочей силы на промышленных предприятиях в городах и сельской местности. В Ярославской и Костромской губерниях военнопленные были обеспечены горячим питанием, жили в отапливаемых бараках, что полностью соответствовало международным соглашениям. Всем оказывалась медицинская помощь, власти старались соблюдать в их отношении санитарные правила.

Население Ярославской и Костромской губерний проявило по отношению к пленным гуманное отношение и христианское сострадание. Некоторые после освобождения остались в России, вступив в брак с русскими женщинами.

\section{Ссылки}

1. Ж Жанов Н. М. Русские военнопленные в мировой войне 1914-1918 гг. М., 1920. 376 c. 
2. Корнеев В. В. Концентрационные лагеря в России в годы Первой мировой войны // Военно-исторический журнал. 2015. № 9. С. 40-43.

3. Ниманов Б. И. Содержание иностранных военнопленных на территории России в годы Первой мировой войны // Вестник РУДН. Серия История России. 2009. № 2. С. 53-61.

4. Государственный архив Костромской области (ГАКО). Ф. 223. Оп. 1. Д. 315.

5. Рыбинские известия. 2013. № 91.

6. Рыбинский фрилиал Государственного архива Ярославской области (РыбФ. ГАЯО). Ф. 104. Оп. 1. Д. 18.

7. Государственный архив Ярославской области (ГАЯО) Ф. 1150. Оп. 2. Д. 1008.

8. ГАЯО. Ф. 1150. Оп. 2. Д. 1007.

9. ГАЯО. Ф. 934. Оп. 1. Д. 1249.

10. ГАКО. Ф.135. Оп. 1. Д. 2385.

11. ГАЯО. Ф. 509. Оп. 1. Д. 1651.

12. Познахирев В. В. Турецкие военнопленные и гражданские пленные в России в 1914-1924 гг.: монография. СПб.: Нестор-История, 2014. 118 с.

13. ГАКО. Ф. 799. Оп. 1. Д. 15. 